\title{
Game as a mediator in a first year architectural design education
}

Emel Birer*,

Suggested Citation:

A $\quad A$

C $A$ A $A \cap$

$A$ A

Abstract 
c $A$ A A $\cap$ A A A $A$

1. Introduction 
2. First Year Architectural Design Education 
3. First-Year Architectural Design Education and Game 
C A A A $n$ AA A $A$ 
A

c $A$

A $A \cap$

A A

A

A

4. Case Study- City Game

242 

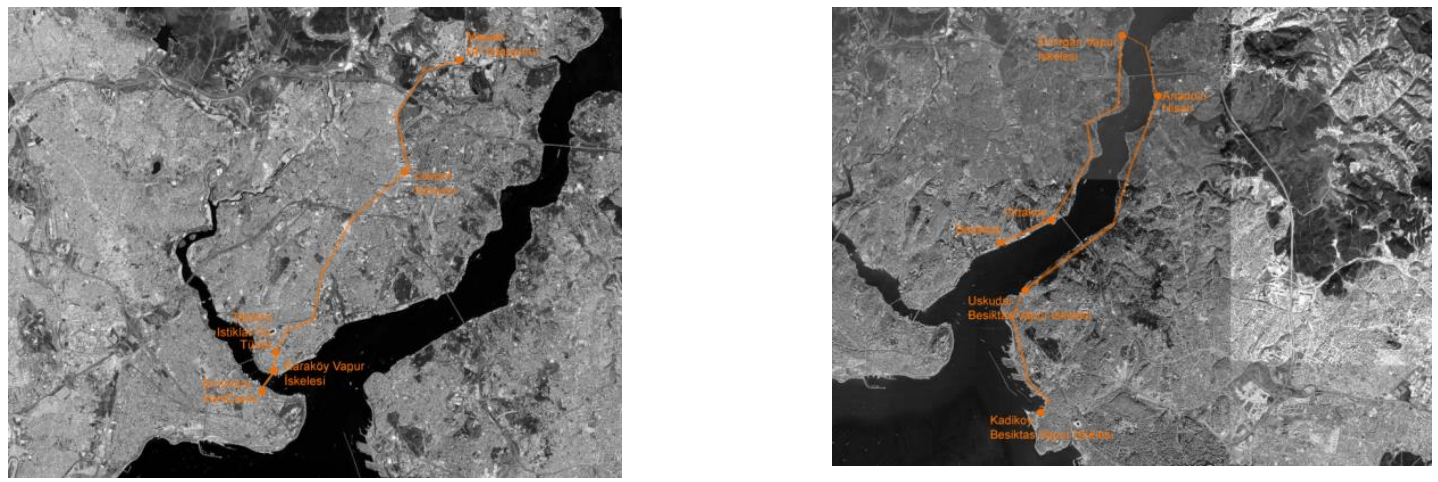

$\begin{array}{llllllllll}A & A & A & & A & A & A & n & A \text { Afb } \cap A & A\end{array}$ 

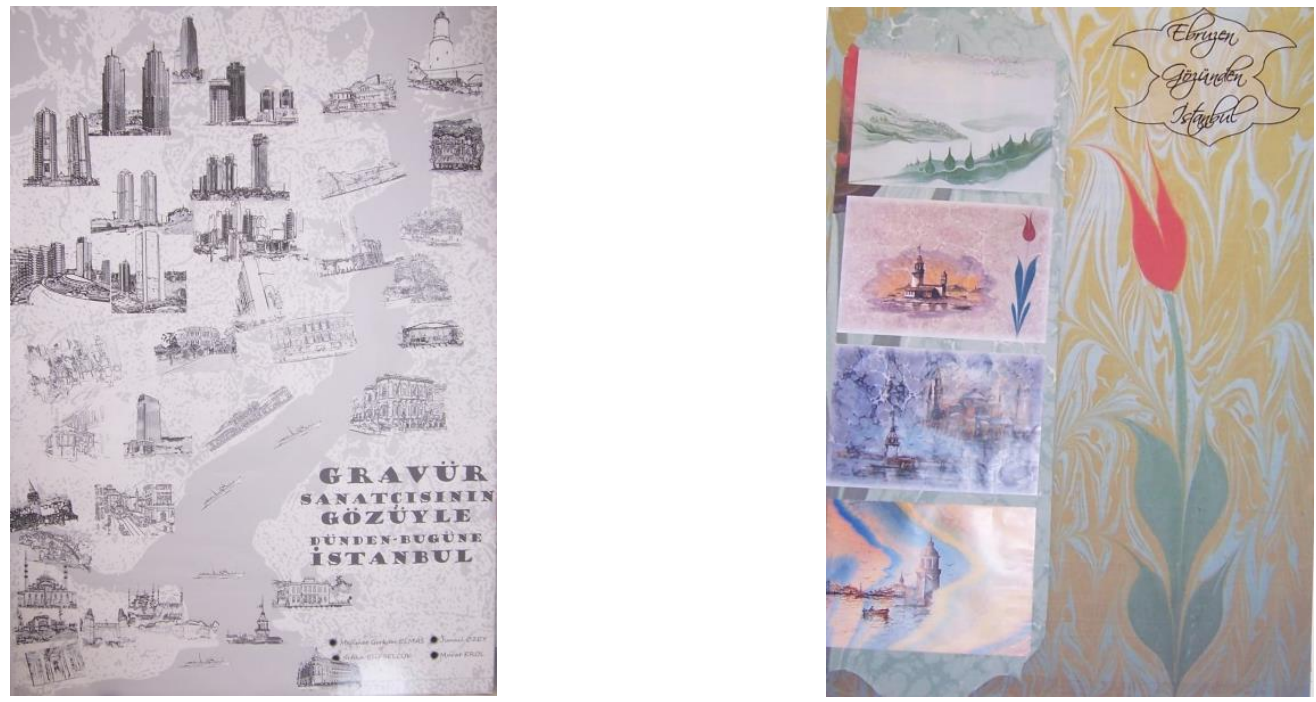

$A$

$$
\begin{array}{llllllllllllll}
A & A & A & n & A & A & A A D & A & A B & A
\end{array}
$$



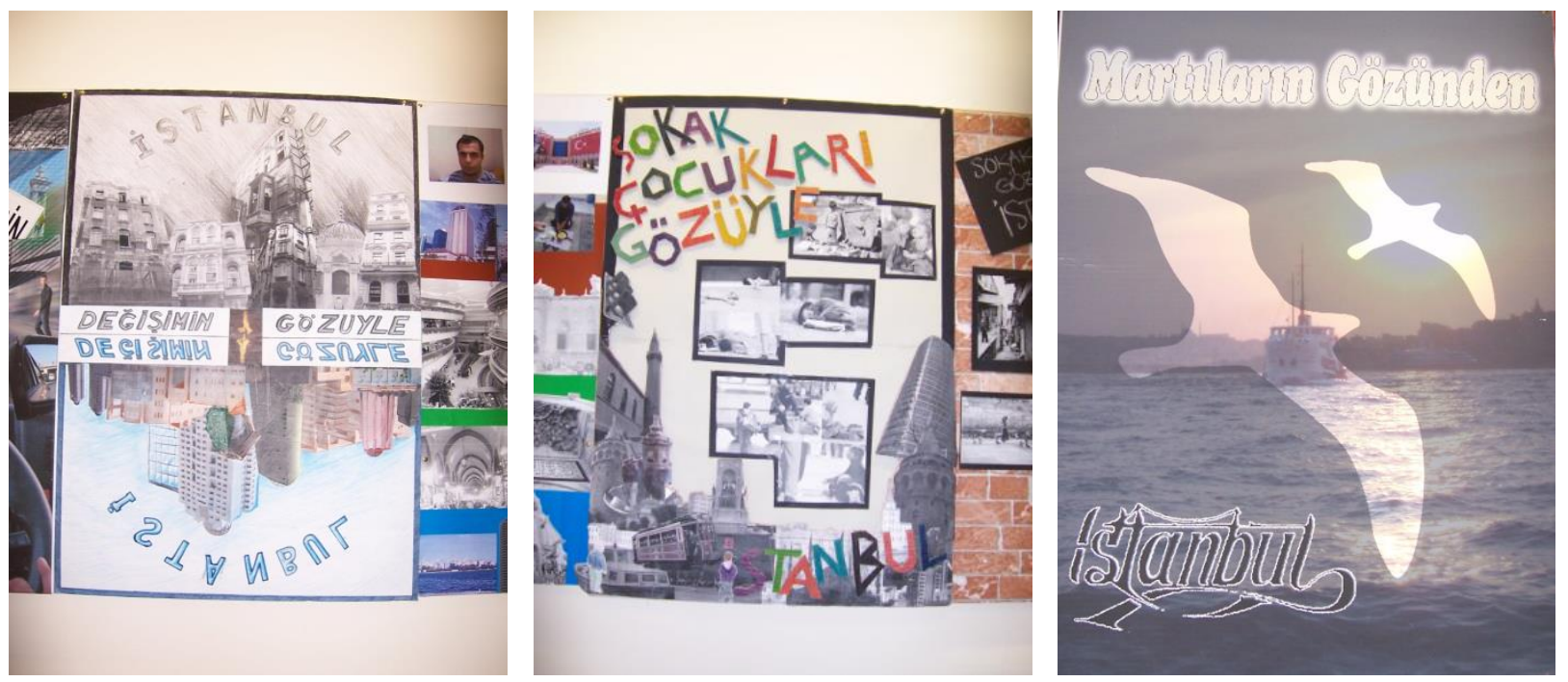

AN A A AN $C$ AA A A A A A A A
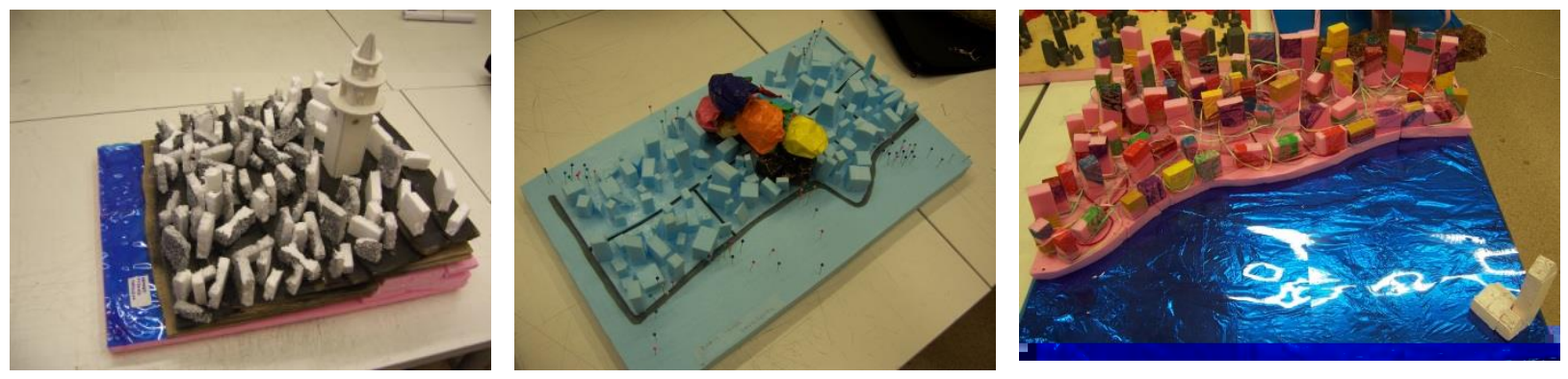
A $\quad A \quad A$
$A A A A$
A A w $\cap \quad A A$
A $A$
$A J A$ 

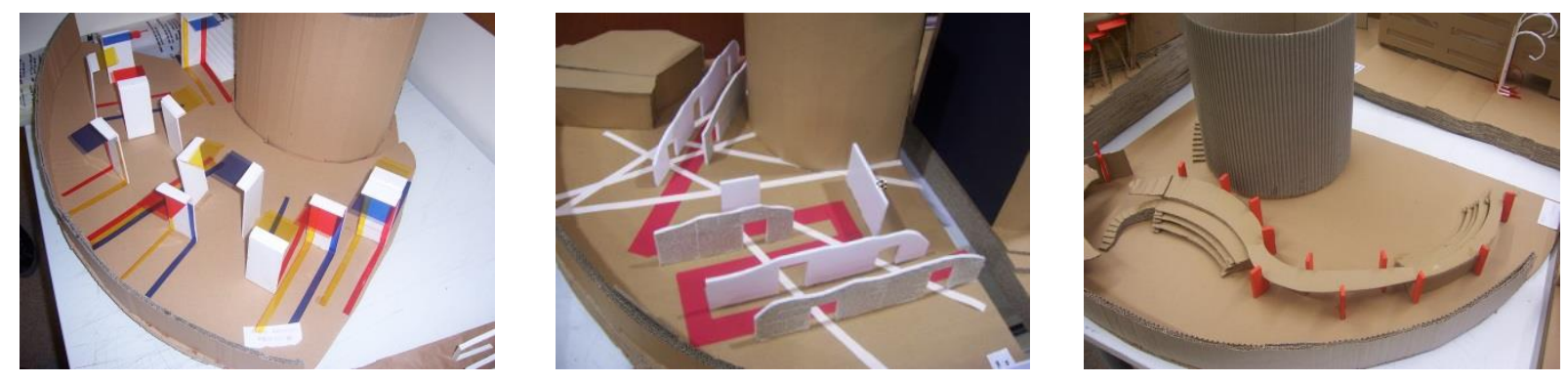

\section{Conclusion}

\section{Acknowledgements}

\section{References}

$$
\begin{aligned}
& \begin{array}{lllllllllll}
A & A & A & A & A & A & A & A & A & A & A
\end{array}
\end{aligned}
$$

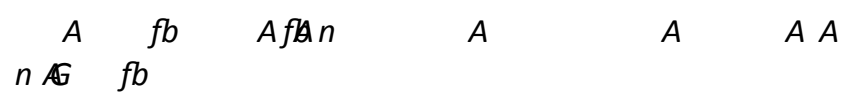

N $\cap \quad A \quad A$

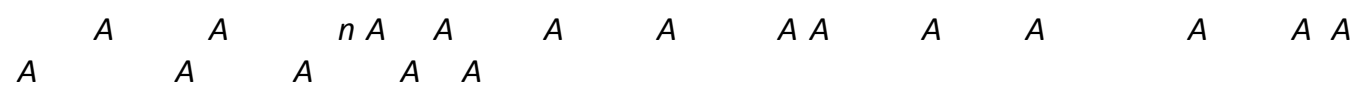

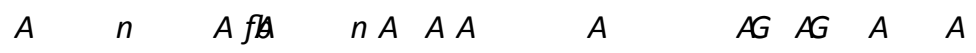



$N n$ ANA $n \mathbb{G}$ NAA $A$

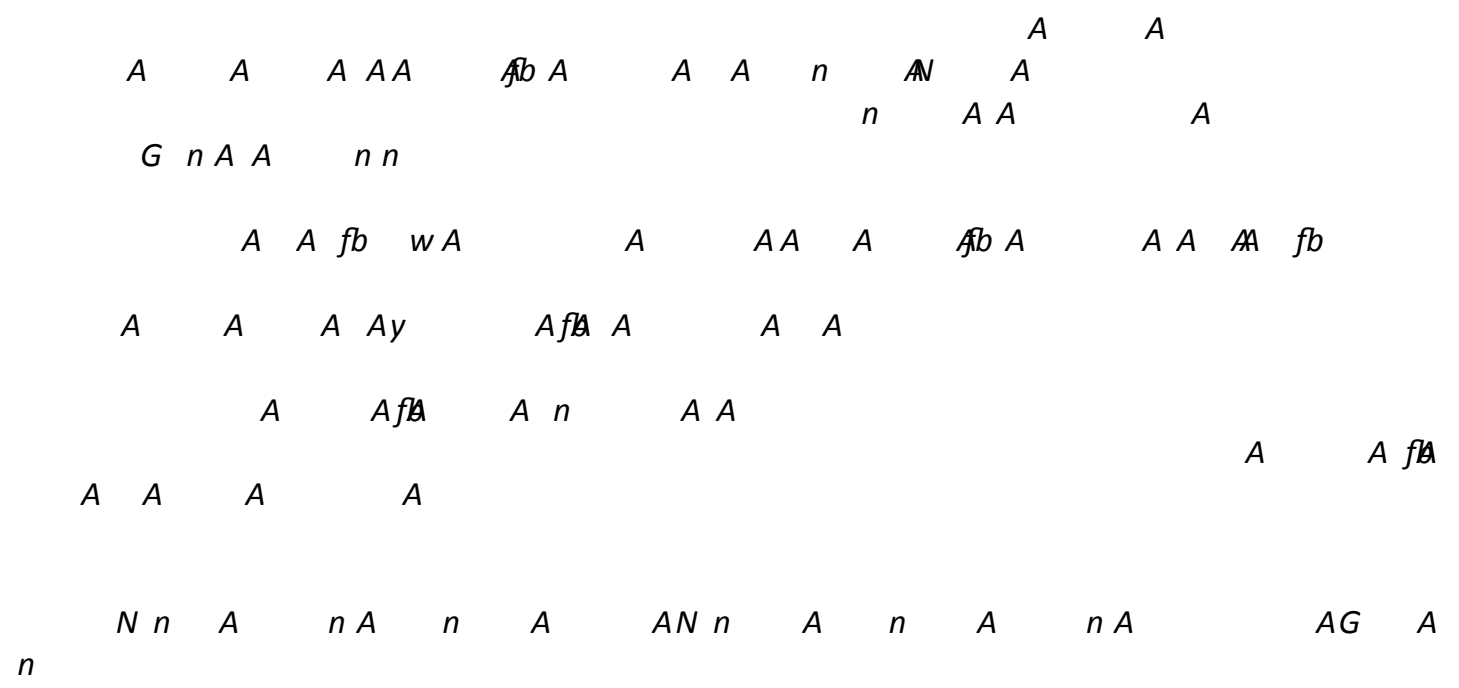

